\title{
Anti-Tuberculosis Drug Resistance in Strains of Mycobacterium tuberculosis Isolated from Patients in a Tertiary Hospital in Bahia
}

\begin{abstract}
Eliana Dias Matos ${ }^{1,3}$, Antônio Carlos Moreira Lemos ${ }^{1,2,4}$, Carolina Bittencourt ${ }^{1}$ and Cristiane Leite Mesquita ${ }^{1}$ ${ }^{1}$ Pneumologist, Octávio Mangabeira Hospital; ${ }^{2}$ Adjunct Professor, Department of Medicine, School of Medicine, Federal University of Bahia; ${ }^{3}$ Assistant Professor, Department of Medicine, Bahia School of Medicine and Public Health; ${ }^{4}$ Coordinator of the Pneumology Research Unit of the Octávio Mangabeira Hospital; Salvador, Bahia, Brazil
\end{abstract}

\begin{abstract}
Anti-tuberculosis drug resistance, particularly multiresistance, is a crucial issue in the control of tuberculosis (TB). This study estimated the prevalence of primary and acquired anti-tuberculosis drug resistance in strains of Mycobacterium tuberculosis isolated from hospitalized patients, to identify the risk factors for resistance, and to evaluate the its impact on hospital mortality for tuberculosis. Strains of Mycobacterium tuberculosis from 217 patients hospitalized for TB were analyzed. Subjects were recruited sequentially at a TB reference hospital in Salvador, Bahia, Brazil from July 2001 to July 2003. Multiresistant (MR) strains were defined as strains resistant to rifampicin and isoniazid. Of a total of 217 strains isolated, $41(19.0 \%, 95 \%$ CI: 14.1-24.5\%) were resistant to at least one drug. Prevalence of primary resistance was $7.0 \%(10 / 145)$, while a prevalence of $43.1 \%(31 / 72)$ was found for acquired resistance. Primary resistance to one drug alone was found in $2.1 \%(3 / 145)$ and acquired monoresistance in 5.6\% (4/72). Prevalence of MR strains in general was $14.3 \%(31 / 217)$, of which $4.2 \%(6 / 145)$ consisted of primary MR and $34.7 \%(25 / 72)$ of acquired MR. Three strains showed resistance to more than one drug, but were not classified as MR. In the multivariate analysis, abandoning treatment remained strongly associated with resistance (adjusted OR: 7.21; 95\% CI: 3.27-15.90; p<0.001) following adjustment for 3 potential confounders (gender, alcohol dependence and HIV-infection). An association was found between resistance and mortality from tuberculosis, even after adjustment for HIV status, age, sex and alcohol dependence (adjusted OR: 7.13; 95\% CI: 2.25-22.57; p<0.001). High prevalences of resistance, principally acquired resistance including MR, were found in patients hospitalized for TB in Bahia. This finding was strongly associated with having abandoned treatment, and confirmed the need to standardize the procedure for requesting sensitivity tests in this population at the time of hospital admission. Key-Words: Mycobacterium tuberculosis, tuberculosis, resistance, multiresistance, hospitals, Bahia-Brazil.
\end{abstract}

The control of tuberculosis (TB) still represents an important challenge in public health, particularly in underdeveloped or developing countries such as Brazil. The World Health Organization (WHO) lists Brazil in $15^{\text {th }}$ place among the 22 countries with the highest TB rates in the world [1].

The state of Bahia is the third in the number of notified cases of TB in Brazil, with around 7,000 new cases per year (approximately $10 \%$ of all cases registered in the country). Around $40 \%$ of these cases occur in the capital city of Salvador, which has a high annual incidence of the disease (108 new cases/ 100,000 inhabitants), making it one of the municipalities in which control of the disease is most difficult and one of the target priorities of the Ministry of Health for the control of TB [2].

Anti-TB drug resistance, and particularly multiresistance, has been a subject of concern worldwide and is the result, in the great majority of cases, of the failure or inadequacy of programs for the control of tuberculosis. In developed countries, many publications in recent years have focused on the phenomenon of $M$. tuberculosis resistance to anti-TB

Received on 30 January 2007; revised 15 May 2007.

Address for correspondence: Dr. Eliana Dias Matos. Associação Baiana de Apoio ao Controle da Tuberculose (ABACONTT)/Núcleo de Pesquisa em Pneumologia (NUPEP)/HEOM. Praça Conselheiro João Alfredo, s/no ${ }^{\circ}$ Pau Miúdo. Zip code: 40.320-350 Salvador, Bahia, Brazil. Telephone: +55 (71)3386-4122 (Ext. 233/272), 3276-1595, 3276-4127, 9135-7457. E-mail: elianadmatos@terra.com.br; abacontt@ig.com.br.

The Brazilian Journal of Infectious Diseases

2007;11(3):331-338. (C) 2007 by The Brazilian Journal of Infectious Diseases and Contexto Publishing. All rights reserved. drugs with an emphasis on variations in prevalence rates and regional profiles [3-9]. The elevated prevalence rates of antiTB drug resistance (both primary and multi-resistance), which have been reported in the countries that comprised the former Soviet Union, particularly in confined populations such as in prisons, currently constitute one of the most important issues in public health worldwide [10,11].

In Brazil, data referring to anti-TB drug resistance are sparse. A national survey of resistance carried out by the Ministry of Health between 1996 and 1997 in samples from 6,000 outpatients throughout the country found rates of primary resistance of $9.2 \%$ and acquired resistance of $21.8 \%$ [12]. Other studies carried out in Brazil have reported varying prevalence rates according to the region and the profile of the study population (hospitalized patients or health center outpatients) [13-21]. In Bahia, the only available data are incomplete and consist only of findings from the state's participation in the national multicenter study [12].

The objectives of this present study were: 1) to evaluate the prevalence of primary and acquired resistance of strains of Mycobacterium tuberculosis isolated in hospitalized patients; 2) to identify factors associated with the occurrence of resistance; and 3) to evaluate their impact on hospital mortality for TB.

\section{Materials and Methods}

Cultures for mycobacteria from patients who participated in a prospective cohort study to identify factors associated with hospital mortality from TB were evaluated. A total of 396 
patients, sequentially hospitalized with a diagnosis of TB at the Octávio Mangabeira specialized hospital in Salvador, Bahia, Brazil between July 2001 and July 2003, were selected to participate in the study. The Octávio Mangabeira is a tertiary public hospital that is a reference center for TB and other pneumopathies for the entire state of Bahia, receiving patients from the capital (Salvador) and rural areas. It has 218 beds of which $60 \%$ are exclusively for TB patients, and deals with around $85 \%$ of all hospitalizations for TB in the state.

The diagnosis of TB was made according to the criteria established by the amended Brazilian Guidelines for Tuberculosis: 1) detection of acid-fast bacilli in sputum direct microscopy (Ziehl-Neelsen method) and/or positive culture for M. tuberculosis (in Löwenstein-Jensen medium); 2) clinical, epidemiological and radiological findings compatible with TB, associated with a favorable response to treatment with antiTB drugs [22]. Acid-fast bacilli-positive cases with a culture showing non-tuberculous mycobacteria (NTM) were excluded.

Demographic, clinical and epidemiological data were collected prospectively at the time of hospital admission by a team of medical students using a semi-structured interview instrument that contained, among others, the following variables: age, gender, tobacco use, alcohol dependence, previous anti-TB treatment, previous hospitalization for TB, and history of having abandoned treatment. The CAGE questionnaire, validated in Brazilian studies and widely used in research protocols involving TB patients, was used to define alcohol dependence [23]. For the purpose of analysis, patients who stated that they did not consume alcohol and those who consumed alcohol but whose CAGE questionnaire was negative $(<2$ positive answers) were considered not to be alcohol-dependent.

Cultures for mycobacteria were requested on the day of hospital admission, while sputum samples were systematically collected on the day following admission, irrespective of medical indication. All cultures were performed in LöwensteinJensen medium at the laboratory of the Octávio Mangabeira Hospital in accordance with the standardized guidelines determined in the Ministry of Health's Bacteriology Manual [24]. Tests of sensitivity to anti-TB drugs were carried out at the Central Laboratory for Public Health in accordance with the proportion method proposed by Canetti et al. [25]. Cases of multiresistance were defined as sensitivity tests indicating simultaneous resistance to rifampicin $(\mathrm{R})$ and isoniazid $(\mathrm{H})$ regardless of whether they were associated with resistance to other anti-TB drugs or not. HIV-1 and -2 testing was requested for all patients irrespective of the presence of risk factors for HIV infection, and tests were carried out at the Central Laboratory for Public Health using the ELISA method (as screening) with confirmation by Western Blot or indirect immunofluorescence whenever ELISA was positive. All cultures that were positive for mycobacteria, later confirmed as $M$. tuberculosis using biochemical methods, were included in the study. Exclusion criteria comprised: 1) contamination of the culture material; and 2) inability to perform the sensitivity test for technical reasons such as, for example, insufficient number of colonies of $M$. tuberculosis in the culture.

The project was submitted to and approved by the Internal Review Board of the Edgard Santos Teaching Hospital of the Federal University of Bahia, and all participants signed an informed consent form prior to admission.

\section{Data Analysis}

Data analysis was carried out using the SPSS software program, version 9.0. Continuous and categorical variables were compared using Student's t-test and the chi-square test (or Fisher's Exact test, when indicated), respectively. Odds ratio was the association measurement used. Univariate analysis was carried out to identify possible risk factors for anti-TB drug resistance. Multivariate analysis using the logistic regression method was used to adjust for any potential confounders. Variables with $\mathrm{p}<0.2$ in the univariate analysis were included in the multivariate model. Statistical significance was established as $\mathrm{p}<0.05$.

\section{Results}

Of the 396 patients initially eligible for the study, mycobacteria cultures were carried out in 337 (85.1\%). Of these, 21 were contaminated $(6.2 \%)$ and were excluded from the study. Of the 316 remaining cultures, 45 (14.2\%) were negative and 271 $(85.7 \%)$ were positive. Of the 271 cultures that were positive for M. tuberculosis, sensitivity tests were available for analysis in $217(80.1 \%)$ and these constituted the final study sample. Of the 217 patients in the study, 207 (95.4\%) were sputum smearpositive, with bacillary loads graded as: $1+(30.9 \%-64 / 207) ; 2+$ (27.1\% - 56/207); and 3+(42.0\% -87/207).

Table 1 shows the demographic, clinical and epidemiological characteristics of the study population. Mean age \pm standard deviation (SD) was $39.2 \pm 14.1$ years, and $77.0 \%$ of patients $(167 / 217)$ were male. Alcohol dependence was reported by $55.8 \%$ of patients $(121 / 217)$ and tobacco use by $54.4 \%(118 / 217)$. Serology for HIV infection was positive in $6.9 \%$ of patients $(15 / 217)$. Of the 217 patients, $72(33.2 \%)$ reported having undergone previous treatment for TB, and 59 $(27.2 \%)$ had a history of having abandoned previous treatment. Previous hospitalization for TB was reported by $21.2 \%$ of patients (46/217). No statistically significant differences in age, sex or tobacco use were found between the groups of patients with drug-resistant strains and the group with sensitive strains. With respect to HIV infection, a greater number of patients with resistant strains were found to have HIV co-infection compared to the group with sensitive strains ( $12.2 \%$ versus $5.7 \%$ ); however, this difference was not statistically significant $(\mathrm{p}=0.161$ ). Statistically significant differences were found in the group with drug-resistant strains compared to the group with no resistance with respect to the following variables: history of previous treatment with antiTB drugs ( $75.6 \%$ versus $23.3 \%$; $\mathrm{p}<0.001)$; having previously abandoned anti-TB treatment $(61.0 \%$ versus $19.3 \% ; \mathrm{p}<0.001)$, 
Table 1. Demographic, clinical and epidemiological characteristics of the total population and according to the general resistance of the isolated M. tuberculosis strains

\begin{tabular}{|c|c|c|c|c|}
\hline Characteristics & $\begin{array}{c}\text { Resistant } \\
(\mathrm{n}=\mathbf{4 1})\end{array}$ & $\begin{array}{c}\text { Sensitive } \\
(n=176)\end{array}$ & $\begin{array}{c}\text { Total } \\
(n=217)\end{array}$ & p value \\
\hline \multicolumn{5}{|l|}{ Age (years) } \\
\hline Mean \pm SD & $37.9 \pm 13.8$ & $39.5 \pm 14.1$ & $39.2 \pm 14.1$ & NS \\
\hline Range & $16-80$ & $16-80$ & $16-80$ & \\
\hline Males, n (\%) & $28(68.3)$ & $139(79.0)$ & $167(77.0)$ & NS \\
\hline Alcohol dependenceY, n (\%) & $14(34.1)$ & $107(60.8)$ & $121(55.8)$ & $0.002 *$ \\
\hline Tobacco use, $\mathrm{n}(\%)$ & $21(51.2)$ & $97(55.1)$ & $118(54.4)$ & NS \\
\hline $\mathrm{HIV}+, \mathrm{n}(\%)$ & $5(12.2)$ & $10(5.7)$ & $15(6.9)$ & NS \\
\hline Previous anti-TB treatment, $\mathrm{n}(\%)$ & $31(75.6)$ & $41(23.3)$ & $72(33.2)$ & $<0.001 *$ \\
\hline History of abandoning treatment, $\mathrm{n}(\%)$ & $25(61.0)$ & $34(19.3)$ & $59(27.2)$ & $<0.001 *$ \\
\hline Previous hospitalization, $\mathrm{n}(\%)$ & $21(51.2)$ & $25(14.2)$ & $46(21.2)$ & $<0.001 *$ \\
\hline
\end{tabular}

$\mathrm{Y}=$ alcohol dependence defined according to the CAGE questionnaire. *Statistically significant difference. NS=not statistically significant.

and prior hospitalization for TB (51.2\% versus $14.2 \%$; $<<0.001)$. Paradoxically, alcohol dependence was more frequent in the group with sensitive strains compared to the group with resistant strains $(60.8 \%$ versus $34.1 \%$; $<<0.002)$.

Forty-one out of the total of 217 strains evaluated were found to be resistant to at least one drug $(19.0 \%$; $95 \% \mathrm{CI}$ : 14.1 $24.5 \%$ ). Table 2 shows the patterns of resistance to one or more anti-TB drugs according to history of previous treatment. One hundred forty-five of the 217 patients $(66.8 \%)$ were treatment-naïve and $32.2 \%(72 / 217)$ reported a history of previous treatment. Primary resistance was found in $7.0 \%$ (10/ $145)$ and acquired resistance in $43.1 \%$ (31/72) of the strains analyzed. Resistance to only one drug (monoresistance) was found in seven patients, primary monoresistance in $2.1 \%$ (3/ 145 ) and acquired monoresistance in 5.6\% (4/72). Resistance to only one drug was as follows: rifampicin (R): primary resistance $0.7 \%$ (1/145), no strains with acquired resistance; isoniazid $(\mathrm{H})$ : no strains with primary resistance, acquired resistance $1.4 \%(1 / 72)$; streptomycin $(\mathrm{S})$ : primary resistance $0.7 \%(1 / 145)$, acquired resistance $4.2 \%$ (3/72); ethionamide (Et): primary resistance $0.7 \%(1 / 145)$, no strains with acquired resistance. No strains with mono-resistance to pyrazinamide (Z) or ethambutol (E) were found. With respect to resistance to two drugs, $2.8 \%$ (4/145) of strains were found to have primary resistance, of which $2.1 \%(3 / 145)$ were resistant to $\mathrm{R}+\mathrm{H}$ and $0.7 \%(1 / 145)$ to $\mathrm{H}+\mathrm{S}$. In $11.1 \%(8 / 72)$, only multiresistant patterns of acquired resistance to two drugs were found. Resistance to three drugs was found in six strains, in $1 / 145(0.7 \%)$ primary resistance to $\mathrm{R}+\mathrm{H}+\mathrm{S}$ and in $5 / 72(6.9 \%)$ acquired resistance as follows: $\mathrm{R}+\mathrm{H}+\mathrm{S} 2.7 \%(2 / 72), \mathrm{R}+\mathrm{H}+\mathrm{Et}$ $1.4 \%$ (1/72), H+E+S 1.4\% (1/72), H+E+Et 1.4\% (1/72). Sixteen strains were found to have patterns of resistance to four or more drugs, $1.4 \%(2 / 145)$ of which were primary resistance and $19.5 \%$ (14/72) acquired resistance. All 16 strains were classified as MR.

Therefore, of the 217 strains isolated, 31 (14.2\%) were classified as MR, $4.2 \%$ (6/145) being primary MR and $34.7 \%$ (25/72) acquired MR. Among the strains with some type of resistance, $75.6 \%$ (31/41) were classified as multiresistant. Table 3 lists the percentage distribution of primary and acquired MR patterns.

In the univariate analysis, general resistance to anti-TB drugs was significantly associated with: history of previous treatment, having abandoned treatment, and previous hospitalization. In addition, an inverse association with alcohol dependence was found. The variables concerning age, gender, tobacco use and anti-HIV serology were not significantly associated with resistance (Table 4). The variables concerning gender, alcohol dependence, anti-HIV serology and having abandoned treatment were included in the multivariate model since they generated a $p<0.2$ in the univariate analysis. The variables regarding previous treatment and prior hospitalization were considered as being colinear to having abandoned treatment, i.e. they represented the same phenomenon; therefore, they were not included in the multivariate model. In the multivariate analysis (Table 5), to adjust for potential confounders identified in the univariate analysis (gender, alcohol dependence, HIV infection), the fact that the patient had abandoned previous treatment remained strongly associated with general resistance to anti-TB drugs (adjusted OR: 7.21; 95\%CI: 3.27-15.90; $\mathrm{p}<0.001$ ). An inverse association was also found between alcohol dependence and anti-TB drug resistance (adjusted OR 0.30; 95\% CI: 0.13-0.68; $\mathrm{p}=0.004)$.

Hospital mortality from TB (Table 6) was highest in the group of patients with strains of $M$. tuberculosis that were resistant to at least one drug compared to the group of sensitive strains (19.5\% versus $4.5 \%$; unadjusted OR 5.56; 95\% CI: 2.00-15.43; $\mathrm{p}=0.010)$. This association remained positive and statistically significant following adjustment for age, gender, HIV status and alcohol dependence (adjusted OR: 7.13; $95 \%$ CI: 2.25-22.57; $\mathrm{p}<0.001$ ).

\section{Discussion}

The present study found a high prevalence of resistance to at least one anti-TB drug (19\%) in patients hospitalized in 
Table 2. Resistance to one or more drugs in the cultures of patients with $\mathrm{TB}$, according to history of previous treatment $(\mathrm{n}=217)$

\begin{tabular}{|c|c|c|c|c|}
\hline \multirow[t]{2}{*}{ Results } & \multicolumn{2}{|c|}{ Primary resistance $(n=145)$} & \multicolumn{2}{|c|}{ Acquired resistance $(n=72)$} \\
\hline & $\mathbf{N}$ & $\%$ & $\mathbf{N}$ & $\%$ \\
\hline \multicolumn{5}{|l|}{ Resistance to 1 drug* } \\
\hline $\mathrm{R}$ & 1 & 0.7 & 0 & 0 \\
\hline $\mathrm{H}$ & 0 & 0 & 1 & 1.4 \\
\hline $\mathrm{S}$ & 1 & 0.7 & 3 & 4.2 \\
\hline $\mathrm{Et}$ & 1 & 0.7 & 0 & 0 \\
\hline Total & 3 & 2.1 & 4 & 5.6 \\
\hline \multicolumn{5}{|l|}{ Resistance to 2 drugs } \\
\hline $\mathrm{R}+\mathrm{H}$ & 3 & 2.1 & 8 & 11.1 \\
\hline $\mathrm{H}+\mathrm{S}$ & 1 & 0.7 & 0 & 0 \\
\hline Total & 4 & 2.8 & 8 & 11.1 \\
\hline \multicolumn{5}{|l|}{ Resistance to 3 drugs } \\
\hline $\mathrm{R}+\mathrm{H}+\mathrm{S}$ & 1 & 0.7 & 2 & 2.7 \\
\hline $\mathrm{R}+\mathrm{H}+\mathrm{Et}$ & 0 & 0 & 1 & 1.4 \\
\hline $\mathrm{H}+\mathrm{E}+\mathrm{S}$ & 0 & 0 & 1 & 1.4 \\
\hline $\mathrm{H}+\mathrm{E}+\mathrm{Et}$ & 0 & 0 & 1 & 1.4 \\
\hline Total & 1 & 0.7 & 5 & 6.9 \\
\hline \multicolumn{5}{|c|}{ Resistance to $=4$ drugs } \\
\hline $\mathrm{R}+\mathrm{H}+2$ drugs & 1 & 0.7 & 8 & 11.1 \\
\hline $\mathrm{R}+\mathrm{H}+3$ drugs & 1 & 0.7 & 3 & 4.2 \\
\hline $\mathrm{R}+\mathrm{H}+4$ drugs & 0 & 0 & 3 & 4.2 \\
\hline Total & 2 & 1.4 & 14 & 19.5 \\
\hline Total & 10 & 7.0 & 31 & 43.1 \\
\hline
\end{tabular}

$\mathrm{R}=$ rifampicin; $\mathrm{H}=$ isoniazid; $\mathrm{Z}=$ pyrazinamide; $\mathrm{E}=$ ethambutol; $\mathrm{S}=$ streptomycin; Et=ethionamide. *No strains with isolated resistance to $\mathrm{E}$ and $\mathrm{Z}$ were found.

Table 3. Primary and acquired multiresistance of strains of $M$. tuberculosis from hospitalized patients $(\mathrm{n}=217)$

\begin{tabular}{lccccc}
\hline & \multicolumn{2}{c}{$\begin{array}{c}\text { Primary multiresistance } \\
(\mathbf{n = 1 4 5})\end{array}$} & & \multicolumn{2}{c}{$\begin{array}{c}\text { Acquired multiresistance } \\
(\mathbf{n}=\mathbf{7 2})\end{array}$} \\
\cline { 2 - 3 } \cline { 5 - 6 } & $\mathbf{N}$ & $\mathbf{\%}$ & & $\mathbf{N}$ & \% \\
\hline $\mathrm{R}+\mathrm{H}$ & 3 & 2.1 & & 8 & 11.1 \\
$\mathrm{R}+\mathrm{H}+\mathrm{S}$ & 1 & 0.7 & & 2 & 2.7 \\
$\mathrm{R}+\mathrm{H}+\mathrm{Et}$ & 0 & 0 & & 1 & 1.4 \\
$\mathrm{R}+\mathrm{H}+2$ drugs & 1 & 0.7 & & 8 & 11.1 \\
$\mathrm{R}+\mathrm{H}+3$ drugs & 1 & 0.7 & & 3 & 4.2 \\
$\mathrm{R}+\mathrm{H}+\mathrm{S}+\mathrm{E}+\mathrm{Z}+\mathrm{Et}$ & 0 & 0 & & 3 & 4.2 \\
Total & 6 & 4.2 & & 25 & 34.7 \\
\hline
\end{tabular}

R=rifampicin; H=isoniazid; $Z$ =pyrazinamide; E=ethambutol; $S=$ streptomycin; Et=ethionamide.

Bahia. The estimated prevalence of primary resistance $(7.0 \%)$ was close to that found in a multicenter study $(9.2 \%)$ carried out by the Ministry of Health; nevertheless, the prevalence of acquired resistance (43.1\%) was higher (around twice as high) as that found in the aforementioned study (21.8\%) [12]. Some explanations may justify the discordance between the findings of these two studies with respect to acquired resistance: 1) the national survey on anti-TB drug resistance was carried out between 1996 and 1997, and changes may have occurred in these estimates over time; 2 ) the national study evaluated outpatients (6,000 samples from various state capitals around the country), whereas the present study assessed a population of hospitalized patients; consequently, potentially more serious cases with a greater percentage of cases of repeat treatment and history of having abandoned previous treatments; 3 ) regional differences may also partially justify these findings since the national survey reflected the conditions of outpatients in various state capitals around the country (including Salvador, which is the capital city of the state of Bahia), whereas the present study sample was selected from the population of hospitalized patients, exclusively in the state of Bahia.

Fandinho et al. analyzed patterns of anti-TB drug resistance in 265 strains isolated from patients admitted to 
Table 4. Results of the univariate analysis of potential risk factors for general resistance to anti-TB drugs, according to the logistic regression method

\begin{tabular}{|c|c|c|c|}
\hline Variables & Number of patients & Non-adjusted OR (95\%CI) & p-value \\
\hline \multicolumn{4}{|l|}{ Age (vears) } \\
\hline$>40$ & 91 & $0.64(0.32-1.29)$ & \multirow[t]{2}{*}{$0.212 * *$} \\
\hline$\leq 40$ & 126 & reference & \\
\hline \multicolumn{4}{|l|}{ Gender } \\
\hline Masculine & 167 & $0.57(0.27-1.21)$ & \multirow{2}{*}{$0.147 * *$} \\
\hline Feminine & 50 & reference & \\
\hline \multicolumn{4}{|c|}{ Alcohol dependence } \\
\hline Yes & 121 & $0.41(0.12-0.83)$ & \multirow{2}{*}{$0.013^{*}$} \\
\hline No & 96 & reference & \\
\hline \multicolumn{4}{|l|}{ Tobacco use } \\
\hline Yes & 118 & $0.85(0.43-1.69)$ & \multirow{2}{*}{$0.652 * *$} \\
\hline No & 99 & reference & \\
\hline \multicolumn{4}{|l|}{ HIV serology } \\
\hline Positive & 15 & $2.22(0.72-7.42)$ & \multirow[t]{2}{*}{$0.137 * *$} \\
\hline Negative & 202 & reference & \\
\hline \multicolumn{4}{|c|}{ Previous anti-TB treatment } \\
\hline Yes & 72 & $7.96(3.73-16.98)$ & \multirow{2}{*}{$<0.001^{*}$} \\
\hline No & 145 & reference & \\
\hline \multicolumn{4}{|c|}{ History of having abandoned TB treatment } \\
\hline Yes & 59 & $5.80(2.83-11.89)$ & \multirow[t]{2}{*}{$<0.001 *$} \\
\hline No & 158 & reference & \\
\hline \multicolumn{4}{|c|}{ Previous hospitalization for TB } \\
\hline Yes & 46 & $6.34(3.01-13.35)$ & \multirow[t]{2}{*}{$<0.001 *$} \\
\hline No & 171 & reference & \\
\hline
\end{tabular}

*Statistically significant. $* *$ Not statistically significant. OR=odds ratio. $95 \% \mathrm{CI}=95 \%$ confidence interval.

Table 5. Results of the multivariate analysis of potential risk factors for general resistance to anti-TB drugs (logistic regression method)

\begin{tabular}{|c|c|c|c|}
\hline Variables & Unadjusted OR (95\% CI) & Adjusted OR (95\% CI) & p-value \\
\hline \multicolumn{4}{|l|}{ Gender } \\
\hline Masculine & $0.57(0.27-1.21)$ & $1.13(0.47-2.72)$ & $0.780 * *$ \\
\hline Feminine & reference & reference & \\
\hline \multicolumn{4}{|c|}{ Alcohol dependence } \\
\hline Yes & $0.41(0.12-0.83)$ & $0.30(0.13-0.68)$ & $0.004 *$ \\
\hline No & reference & reference & \\
\hline \multicolumn{4}{|l|}{ HIV serology } \\
\hline Positive & $2.22(0.72-7.42)$ & $2.94(0.82-10.44)$ & $0.062 * *$ \\
\hline Negative & reference & reference & \\
\hline \multicolumn{4}{|c|}{ History of having abandoned treatment } \\
\hline Yes & $5.80(2.83-11.89)$ & $7.21(3.27-15.90)$ & $<0.001 *$ \\
\hline No & reference & & \\
\hline
\end{tabular}

*Statistically significant. $* *$ Not statistically significant. OR=odds ratio. $95 \% \mathrm{CI}=95 \%$ confidence interval.

Table 6. Adjusted and unadjusted association between general resistance to anti-TB drugs and hospital mortality (logistic regression)

\begin{tabular}{|c|c|c|c|c|c|}
\hline \multirow[b]{2}{*}{ Status de resistance } & \multicolumn{3}{|c|}{ Death during hospitalization } & \multicolumn{2}{|c|}{ Odds ratio $(95 \% \mathrm{CI})$} \\
\hline & Yes & No & $\%$ of deaths & Unadjusted & Adjustedy \\
\hline Resistant & 8 & 33 & 19.5 & $\begin{array}{c}5.56 \\
(2.00-15.43)^{*}\end{array}$ & $\begin{array}{c}7.13 \\
(2.25-22.57)^{* *}\end{array}$ \\
\hline Sensitive & 8 & 168 & 4.5 & reference & reference \\
\hline
\end{tabular}


two tertiary hospitals in Rio de Janeiro (hospital \#1 being a reference center for AIDS and hospital \#2 a convalescent home) between 1993 and 1994 [20]. These investigators found 44 cases $(16.6 \%)$ of resistance to at least one drug, 17/127 (13.4\%) in hospital \#1 and 27/138 (19.5\%) in hospital \#2. The present study found a prevalence of global resistance more similar to that of hospital \#2, which had the structure of a convalescent home. This finding may be explained by the fact that the characteristics of the clientele were similar between the hospital used in the present study and hospital \#2, with high percentages of patients undergoing retreatment.

More recently, Brito et al. studied 165 patients with TB in a general hospital that is a reference center for AIDS in Rio de Janeiro, and reported general resistance of $20 \%$, similar to that found in the present study [13]. The prevalence of primary resistance, however, was higher than that of acquired resistance (18.4\% and $12.5 \%$, respectively), what contradicts the data from the other Brazilian studies, including this current one. Another study, also carried out in Rio de Janeiro but in an outpatient population, found prevalences of primary resistance of $11.7 \%$ and acquired resistance of $28.8 \%$ [14].

In Natal, in the state of Rio Grande do Norte, in the Northeastern Brazil (the same geographic area as the state of Bahia), a study involving patients in a tertiary reference center $(n=72)$ reported prevalence rates of primary resistance of $17.4 \%$ and acquired resistance of $57.1 \%$, higher than those found in the current study [16]. Nevertheless, although there are similarities between the two studied populations (patients recruited at a tertiary center within the same geographic region of the country), there are variations in certain aspects of the methodology between these two studies: 1) the sample size in the present study is larger (217 patients); 2) the selection bias in the current study is minimal, since cultures and sensitivity tests were carried out prospectively and systematically at the time of admission to hospital regardless of the clinical indication or the medical opinion issued by the attending physician. Another study, carried out in patients undergoing follow-up at the TB outpatient department of the Teaching Hospital of the Federal University of Pernambuco in Recife, a city also situated in the Northeastern Brazil, reported a prevalence rate of general resistance of $21.2 \%$ (63/297) of which primary resistance was $16.2 \%(38 / 234)$ and acquired resistance $39.7 \%(25 / 63)$ [21]. The results of this latter study are similar to those of our study with respect to the prevalence of general resistance and acquired resistance; however, the prevalence of primary resistance was significantly higher in that study compared with the present one $(16.2 \%$ versus $7.0 \%$; $\mathrm{p}=0.014)$.

Mello et al. studied temporal changes in primary resistance in patients being followed up at a tertiary reference center in São Paulo (Southeastern Brazil), and reported progressive, statistically significant reductions in prevalence rates of primary resistance in the sixties, seventies and eighties $(17.2 \%$, $9.6 \%$ and $7.4 \%$, respectively). Data on the prevalence of primary resistance in the present study $(7.0 \%)$ are in agreement with the rates reported by Mello et al for the eighties [18].
Isolated primary resistance to rifampicin, streptomycin and ethionamide was less than $1 \%$, and no strains with isolated primary resistance to isoniazid, ethambutol or pyrazinamide were found in our sample. Considering the different sample sizes proportionately, these data are in agreement with those found in the last national survey [12]. With respect to anti-TB drug multiresistance, the estimated primary and acquired MR rates ( $4.2 \%$ and $34.7 \%$, respectively) found in this study were higher than those reported in the national survey $(1.1 \%$ and $7.1 \%$, respectively) [12]. Some studies carried out in Brazil have also reported prevalence rates of multiresistance lower than those found in the present study, $1.8 \%$ [14] and $3.6 \%$ [13]. Other studies, however, have found much higher prevalence rates of multiresistance $[16,26]$. Barros et al evaluated strains of $M$. tuberculosis isolated in a public health laboratory in Ceará between 1990 and 1999, and found a rate of multiresistance of $17.7 \%$ (266/1500) [26]. On the other hand, Abrantes et al reported an estimated prevalence rate of general multiresistance (primary + acquired) of $22.4 \%$ in a reference center in Rio Grande do Norte $(n=72)$ [16], higher than that found in the present study (14.3\%). One possible explanation for this high proportion of strains that were multiresistant to M. tuberculosis may be the differences in the methodology used and possible selection biases. In our study and in the study carried out by Abrantes et al, the similarities between these two centers, which are state reference centers for patients with multiresistant TB (MRTB), may justify the high rates of multiresistance found. The tertiary hospital used in the present study is a state reference center for MRTB and has an outpatient department and a 218-bed ward.

Höfling et al. evaluated strains of M. tuberculosis $(\mathrm{n}=468)$ isolated in Brazil that were resistant to isoniazid, and found simultaneous resistance to rifampicin in 272 (58.1\%) [27]. KatG gene mutations were found in $60.4 \%$ of the isoniazid-resistant strains, while rpoB gene mutations were found in all the rifampicin-resistant strains tested $(n=25)$. In our study, 33 of the 37 isoniazid-resistant strains $(89.2 \%)$ were also resistant to rifampicin. These differences $(58.1 \%$ versus $89.2 \%$ ) between the two studies may be a result of: 1) differences in the methods used to identify resistance (molecular biology versus proportion method); 2) possible selection bias, since the site of the current study is the only reference center for the care of MRTB patients in the state of Bahia; therefore, a high prevalence rate of combined resistance to rifampicin and isoniazid would be expected; and 3) difference in sample size (468 in the study carried out by Höfling et al. versus 37 in the present study).

The univariate analysis identified three variables as possibly being positively associated with global resistance: previous treatment with anti-TB drugs, having abandoned previous treatment, and prior hospitalization for TB. Nevertheless, in this sample, these three variables represented the same phenomenon and were interpreted as colinears (or interrelated); therefore, their effects canceled each other out when they were entered simultaneously into the multivariate 
model. From the point of view of plausibility, having abandoned treatment was therefore considered to be the most representative phenomenon among the three previouslymentioned variables. In a multicenter study carried out in Brazil to evaluate the effectiveness of therapeutic regimens for MRTB, Dalcolmo et al. cited irregular or incomplete previous treatment as being the most important predictor of multiresistance [28]. Two other studies carried out in a reference center in São Paulo, Brazil, also reported that having abandoned anti-TB treatment was a predictor of multiresistance $[18,29]$. Other studies in which having abandoned treatment was not one of the variables evaluated, emphasized history of previous treatment with anti-TB drugs as a predictor of resistance $[14,21,30]$.

In the present study, alcohol dependence was more frequent in the group with no resistance compared to the group with resistance, and an inverse association with global resistance was found in the univariate analysis that persisted following adjustment in the multivariate analysis. No plausible biological reason was found for this fact and it may be attributable to numerical differences between the two groups (sensitivity and resistance). Since abandoning treatment was associated with alcohol dependence in this sample, it is possible that an increase in sample size with a consequent increase in the number of individuals in the resistant group may have modified the numerical disproportions of the percentage of alcohol dependence in the two comparison groups, thereby inverting the results observed and annulling the described association. On the other hand, another possible explanation is a bias that may have occurred in the classification of alcohol dependence, causing an imbalance in the proportion of alcoholics in a small group of patients with strains of $M$. tuberculosis resistant to anti-TB drugs (41 individuals).

Finally, the findings of the present study show a strong, independent association between the presence of anti-TB drug resistance and hospital mortality. These data are in agreement with findings reported by other investigators [31-34] and permit us to question the imperious requirement for chemoprophylaxis in home contacts of patients with multiresistant strains, irrespective of age group.

One of the limitations of this study is the fact that the sample population was recruited at a tertiary hospital that is a reference center for pneumopathies and has its own peculiarities. Therefore, the results of the present study cannot be generalized to National Health Service outpatients. Some positive aspects of the present study deserve particular mention, such as the prospective design and systematic collection of sputum samples for cultures and sensitivity tests irrespective of clinical indication. On the other hand, this hospital, despite being a tertiary healthcare center, is responsible for around $85 \%$ of all hospitalizations for TB in Bahia, the study population being representative, therefore, of all patients requiring hospitalization for this condition within the state.
In conclusion, the findings of this study indicate a need to: 1) update surveys on anti-TB drug resistance in Brazil, including not only patients receiving care at basic healthcare centers but also the population of hospitalized TB patients; 2) implementation of biosafety measures, sanitary engineering systems, administrative measures and measures of individual protection within the hospital environment in which patients with TB are hospitalized, particularly in reference hospitals for this disease; and 3) carry out cultures for mycobacteria and sensitivity tests in patients hospitalized for TB.

\section{Acknowledgements}

This study was developed by the Research Unit in Pneumology of the Octávio Mangabeira Specialist Hospital, Bahia State Department of Health. The study was supported by the Department of Pneumology and the Bahia Association for the Support and Control of Tuberculosis.

\section{References}

1. Dye C., Scheele S., Dolin P., et al. Consensus statement. Global burden of tuberculosis: estimated incidence, prevalence, and mortality by country. WHO Global Surveillance and Monitoring Project. JAMA 1999;282(7):677-86.

2. Encerramento dos casos de tuberculose no Brasil 2003. Brasília: Brasil. Ministério da Saúde. Fundação Nacional de Saúde. Departamento de Vigilância Epidemiológica. Área técnica de Pneumologia Sanitária, 2004.

3. Robert J., Trystram D., Truffot-Pernot C., Jarlier V. Multidrugresistant tuberculosis: eight years of surveillance in France. Eur Respir J 2003;22(5):833-7.

4. Yonemaru M., Toyoda T., Shirai T., et al. [Trends in drug-resistant tuberculosis in National Higashisaitama Hospital, 1994-2001]. Kekkaku 2003;78(2):83-7.

5. Bradford W.Z., Martin J.N., Reingold A.L., et al. The changing epidemiology of acquired drug-resistant tuberculosis in San Francisco, USA. Lancet 1996;348(9032):928-31.

6. Koo D., Royce S., Rutherford G.W. Drug-resistant Mycobacterium tuberculosis in California, 1991 to 1992. West J Med 1995; $163(5): 441-5$

7. Shafer R.W., Small P.M., Larkin C., et al. Temporal trends and transmission patterns during the emergence of multidrugresistant tuberculosis in New York City: a molecular epidemiologic assessment. J Infect Dis 1995;171(1):170-6.

8. Salomon N., Perlman D.C., DePalo V.A., et al. Drug-resistant tuberculosis: factors associated with rise in resistance in an HIVinfected urban population. Mt Sinai J Med 1994;61(4):341-8.

9. Vanacore P., Koehler B., Carbonara S., et al.. Drug-resistant tuberculosis in HIV-infected persons: Italy 1999-2000. Infection 2004;32(6):328-32.

10. Drobniewski F., Balabanova Y., Nikolayevsky V., et al. Drugresistant tuberculosis, clinical virulence, and the dominance of the Beijing strain family in Russia. JAMA 2005;293(22):2726-31.

11. Dewan P., Sosnovskaja A., Thomsen V., et al. High prevalence of drug-resistant tuberculosis, Republic of Lithuania, 2002. Int J Tuberc Lung Dis 2005;9(2):170-4.

12. Braga J.U., Barreto A.M., Hijjar M.A. Inquérito epidemiológico da resitência às drogas usadas no tratamento da tuberculose. Relatório final. Rio de Janeiro: Centro de Referência Professor Hélio Fraga/ FUNASA. Ministério da Saúde, 1999.

13. Brito R.S., Gouder C., Lima D.B., et al. Drug-resistant Mycobacterium tuberculosis strains isolated at an AIDS reference center general hospital in Rio de Janeiro. J Bras Pneumol 2004; 30:335-42. 
14. Natal S., Valente J.G., Sánchez A.R., Penna M.L.. Isoniazid and rifampicin resistance and prior treatment for tuberculosis. Cad Saude Publica 2003;19 (5):1277-81.

15. Jardim P.C.R., Zamarioli L.A., Coelho A.G., et al. Resistência do Mycobacterium tuberculosis às drogas no município de Säo Vicente. Rev Inst Adolfo Lutz 2001;60(2):119-123.

16. Abrantes M.R. Perfil de resistência do Mycobacterium tuberculosis às drogas antituberculose em um serviço de referência em NatalRN, 1997-1999. Instituto de Medicina Social. Rio de Janeiro: Universidade do Estado do Rio de Janeiro, 2000:55 p.

17. Gomes C., Rovaris D.B., Severino J.L., Gruner M.F. Perfil de resistência de $M$. tuberculosis isolados de pacientes portadores do HIV/AIDS atendidos em um hospital de referência. J Pneumol 2000;26(1):25-9.

18. Melo F.A.F., Afiune J.B., Ribeiro L.H.G., et al. Resistência primária do $M$. tuberculosis num serviço ambulatorial de referência em Säo Paulo: evoluçäo por três décadas e comparaçäo com outros estudos nacionais. J Pneumol 1996;22(2):3-8.

19. Silva E.A.M., Sato D.N., Telles M.A.S., et al. Perfil de resistência de Mycobacterium tuberculosis no Estado de Säo Paulo, 1986 a 1990. Rev Inst Adolfo Lutz 1992;52(1/2):37-40.

20. Fandinho F., Kritski A., Hofer C., et al. Drug resistance patterns among hospitalized tuberculous patients in Rio de Janeiro, Brazil, 1993-1994. Mem Inst Oswaldo Cruz 1999;94(4):543-7.

21. Albuquerque M.F., Leitao C.C., Campelo A.R., et al. Prognostic factors for pulmonary tuberculosis outcome in Recife, Pernambuco, Brazil. Rev Panam Salud Publica 2001;9(6):368-74.

22. Castelo Filho A., Kritski A.L., Barreto A.W., et al. II Consenso Brasileiro de Tuberculose: Diretrizes Brasileiras para Tuberculose 2004. J Bras Pneumol 2004;30(supl 1):S2-S56.

23. Masur J., Monteiro M.G. Validation of the "CAGE" alcoholism screening test in a Brazilian psychiatric inpatient hospital setting. Braz J Med Biol Res 1983;16(3):215-8.

24. Manual de bacteriologia da tuberculose. Rio de Janeiro: Brasil. Ministério da Saúde. Centro de Referência Professor Hélio Fraga, 1994.
25. Canetti G., Grosset J.H. Techniques et indications des exames bacteriologiques en tuberculose. St. Mande, France: Edition de la Tourelle, 1968.

26. Barroso E.C., Rodrigues J.L.N., Pinheiro V.G.F., Campelo C.L. [Multidrug-resistant tuberculosis prevalence in Ceará StateNortheastern Brazil, 1990-1999]. J Pneumol 2001;27(6):310-4.

27. Höfling C.C., Pavan E.M., Giampaglia C.M., et al. Prevalence of katG Ser315 substitution and rpoB mutations in isoniazidresistant Mycobacterium tuberculosis isolates from Brazil. Int J Tuberc Lung Dis 2005;9(1):87-93.

28. Dalcolmo M.P., Fortes A., Fiuza de Melo A.F., et al. Estudo de efetividade de esquemas alternativos para o tratamento da tuberculose multirresistente no Brasil. J Pneumol 1999; $25: 70-7$.

29. Seiscento M., Melo F.A.F., Ide Neto J., et al. Multiresistant tuberculosis (MRTB): clinical, laboratorial, epidemiological, and therapeutic aspects]. J Pneumol 1997;23(5):237-44.

30. Telzak E.E., Chirgwin K.D., Nelson E.T., et al. Predictors for multidrug-resistant tuberculosis among HIV-infected patients and response to specific drug regimens. Terry Beirn Community Programs for Clinical Research on AIDS (CPCRA) and the AIDS Clinical Trials Group (ACTG), National Institutes for Health. Int J Tuberc Lung Dis 1999;3(3):337-43.

31. Espinal M.A., Kim S.J., Suarez P.G., et al. Standard short-course chemotherapy for drug-resistant tuberculosis: treatment outcomes in 6 countries. JAMA 2000;283(19):2537-45.

32. Mannheimer S.B., Sepkowitz K.A., Stoeckle M., et al. Risk factors and outcome of human immunodeficiency virus-infected patients with sporadic multidrug-resistant tuberculosis in New York City. Int J Tuberc Lung Dis 1997;1(4):319-25.

33. Pablos-Mendez A., Sterling T.R., Frieden T.R. The relationship between delayed or incomplete treatment and all-cause mortality in patients with tuberculosis. JAMA 1996;276(15):1223-8.

34. Palmieri F., Pellicelli A.M., Girardi E., et al. Negative predictors of survival in HIV-infected patients with culture-confirmed pulmonary tuberculosis. Infection 1999;27(6):331-4. 